\title{
A Brief Sailor Resiliency Scale for the South African Navy
}

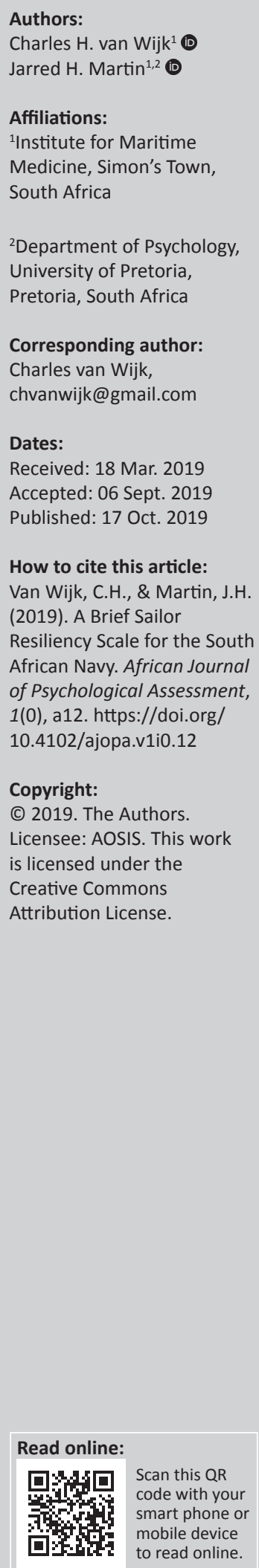

Resilience constructs and measures in the military context are of particular interest because of their association with general performance and mental health outcomes. However, in spite of the reported advantages, the use of resilience assessment models faces two challenges: firstly, measurement and, secondly, operational application within the military environment. This article aimed to provide preliminary validation for a Brief Sailor Resiliency Scale (BSRS) for use in the South African Navy (SAN) in order to discuss its operational application for individuals and groups. The study used a sample of active-duty SAN sailors, distributed throughout the fleet. Participants $(N=1312)$ completed the BSRS, together with established measures of resiliency and emotional regulation, and also provided socio-demographic information. The psychometric structure of the scale was examined, firstly, through confirmatory factor analysis within structural equation modelling, and secondly sociodemographic effects and construct validity were also explored. The model yielded acceptable fit and high internal consistency. Furthermore, the results support the construct validity of the scale. The data appear to support the contention that comprehensive resilience screening measures, while still brief and time-effective, could be employed to the benefit of navy personnel. This would facilitate a 'screen-and-stream' approach which allows military mental health practitioners (1) to screen military personnel comprehensively and (2) to identify and stream quickly those whose resilience appears to be compromised for further assessment and targeted intervention by appropriate support providers.

Keywords: measurement; resilience; South Africa; screen-and-stream; ICE environments.

\section{Introduction}

The Brief Sailor Resiliency Scale (BSRS) is an instrument which aims to measure four core dimensions that are thought to contribute to a comprehensive and global measure of resilience within the military environment, namely mental, physical, social and spiritual fitness. The aim of this article is to demonstrate preliminary validity of the BSRS for local use, in order to discuss the potential operational and, in particular, occupational health applications of the BSRS beyond mere use in resilience research.

\section{Background}

Resilience is the process of adapting well in the face of adversity, trauma, tragedy or threats (American Psychological Association, 2019). A number of constructs fall under the umbrella of resilience, such as hardiness (Kobasa, 1979) and mental toughness (Clough, Earle, \& Sewell, 2002). These constructs are generally conceptualised as psychological orientations that are associated with people who remain healthy and continue to perform well under a range of stressful conditions (Bartone, Roland, Picano, \& Williams, 2008; Kobasa, Maddi, \& Kahn, 1982).

An extensive body of research supports the idea that resilience constructs protect against the ill effects of stress on health and performance among a wide variety of civilian occupations and contexts (Bartone, 1989; Gerber et al., 2015; Giles et al., 2018; Maddi \& Hess, 1992; Maddi \& Kobasa, 1984). In the military, constructs such as hardiness have been shown to influence outcomes among soldiers in various training and combat environments (Bartone, 1996, 1999; Bartone, Johnsen, Eid, Laberg, \& Brun, 2002; Bartone, Ursano, Wright, \& Ingraham, 1989). Hardy soldiers further appear less likely to develop post-traumatic stress disorder (PTSD) and other mental health conditions after combat exposure (Bartone, 1999, 2000; Bartone, Hystad, Eid, \& Brevik, 2012; Escolas, Pitts, Safer, \& Bartone, 2013; Pietrzak, Johnson, Goldstein, Malley, \& Southwick, 2009), and may adapt better both during and after operational deployments (Britt, Adler, \& Bartone, 2001).

Resilience constructs and measures in the military context are of particular importance through their association with general performance and mental health outcomes (Lee, Sudom, \& 
TABLE 1: United States Air Force definitions of four fitness domains.

\begin{tabular}{ll}
\hline Fitness domain & Definition \\
\hline Mental fitness & The ability to cope effectively with unique mental stressors and challenges \\
Physical fitness & The ability to adopt and sustain healthy behaviours needed to enhance health and well-being \\
Social fitness & The ability to engage in healthy social networks that promote overall well-being and optimal performance \\
Spiritual fitness & The ability to adhere to beliefs, principles or values needed to persevere and prevail in accomplishing missions
\end{tabular}

Spiritual fitness

The ability to adhere to beliefs, principles or values needed to persevere and prevail in accomplishing missions

Source: Air Force Instruction 90-506. (2014 April 02). Comprehensive airman fitness (CAF). Washington, DC: Department of the Air Force.

Zamorski, 2013). Military life is traditionally associated with exposure to challenging conditions, where enhanced degrees of personal resilience are known to facilitate positive health benefits (Simmons \& Yoder, 2013) and more meaningful modes of adaptation to the demands of operational work (Morgan \& Bibb, 2011). In certain operational environments, such as those typically faced by naval forces, a number of occupational groups work in isolated, confined and/or extreme (ICE) environments (e.g. on ships and in submarines), which adds an additional layer of potentially stressful environmental circumstances (Smallidge et al., 2013). Moreover, naval deployments have also been shown to give rise to peculiar operationally specific stressors and traumatic exposures, which can act as potential compromisers of sailors' resilience (Martin, Van Wijk, Hans-Arendse, \& Makhaba, 2013). In both instances, enhanced styles of resilience may be particularly beneficial for naval personnel in withstanding the rigours of military work and life. In this regard, the ability to meaningfully measure resilience in military populations has increasingly become important because of the occupational and operational advantages that such research yields (Xie, Peng, Zuo, \& Li, 2016). For example, it helps to identify:

- operationally at-risk individuals, in order to offer additional support

- behavioural targets for intervention

- resilience associated protective, promotive and/or compromising factors

- the effects of interventions on individual or organisational levels.

However, there are challenges when directly measuring psychological resilience by means of psychometric measures, especially in unique ICE environments. Thus, within military contexts, resilience is often assessed through proxies, such as 'adaptation, satisfaction, and other "competent functioning" indicators' (Wright, Riviere, Merrill, \& Cabrera, 2013, pp. 175-176), rather than resilience per se.

As mentioned in the above definition, resilience is conceptualised as an iterative process of adaptation and adaptability. The proxies used to assess it may be considered as expressions of resiliency. Resiliency is conceptualised as an outcome of the resilience process, which - at least in the military - is reflected in the successful performance of important personal and military life roles (Bowen \& Martin, 2011). Sailors' ability (also called readiness) to fulfil their military roles is often referred to as their fitness for duty. Fitness, in this use of the word, is a resilience resource (i.e. a resource that facilitates resiliency). The model investigated in this article provides for four fitness domains, which collate into a total fitness construct, using the United States Air Force (USAF) definitions (see Table 1) that centre on 'ability' to cope and adapt (and that are measured by behavioural outcomes, i.e. resiliency indicators). Total fitness has been reported to have a direct and positive influence on performance-based resiliency (Bowen, Jensen, \& Martin, 2016a; Bowen \& Martin, 2011).

In spite of the reported advantages, the use of resilience/ resiliency models faces two challenges: firstly, measurement and, secondly, operational application in specific contexts.

\section{Measuring fitness in isolated, confined and/or extreme contexts}

There are a multitude of scales available in the general literature that purport to measure aspects of resilience, many of them relatively effective in predicting resilience in the face of real adversity. However, naval - and ICE - environments are often quite unique, and established measures are not always a good fit. Further, tools often measure general dispositional orientation, rather than behaviours in specific contexts. Given the naval context, a measure of behaviours and beliefs may be more useful in that it could provide sailors with a means (e.g. an action) to both measure and enhance their resilience. Thus, fitness-in-context, as a building block of resilience, may be particularly appropriate. Such a scale already exists, having been developed in the USAF context.

Bowen, Jensen and Martin (2016a, 2016b) developed a tool to assess comprehensive airman fitness (CAF), and conducted rigorous factor and multiple group comparison analyses to empirically validate a 12-item measure of the four fitness components and an overall component of comprehensive fitness. Their results verified the presence of the four distinct fitness factors (mental, physical, social and spiritual), each measured with three observed indicators, with high levels of internal consistency within factors. It also demonstrated that the four individual fitness constructs loaded onto a second-order latent construct of total fitness, thus confirming that the four fitness domains can be considered as a total measure of fitness.

Bowen et al. (2016a) further demonstrated construct validity of the CAF measure by using a self-assessed performancebased measure of military resiliency. This measure was defined as a latent factor with three observed variables (Bowen et al., 2016a), and the indicator was derived from measuring human performance within the inherently stressful conditions of military duties and service life (Bowen \& Martin, 2013). Their analyses also showed that the CAF instrument was invariant across subgroups defined by military pay grade, gender, marital status and deployment 
status in the past 12 months - a desirable characteristic of any assessment tool used within a diverse target population such as the military (Bowen et al., 2016b, p. 441).

\section{Operational application of measures}

Measures are typically used as markers of resilience in larger research projects, with their scores then associated with other data that are thought to reflect mental health or performance. However, there has been less discussion on how individual scores could be used to enhance resilience, and presumably mental health, in target groups or larger populations.

The need to develop contextually appropriate and comprehensive measures of resilience in military populations has in recent years become an increasingly topical matter (Adler \& Sowden, 2018; Greene \& Staal, 2017). This is firstly because of the increasing demand on military mental health practitioners (MMHPs) to render health support services - to large numbers of military personnel over the short periods of time that are allotted during pre-and post-deployment readiness and decompression cycles - in far more (cost-) efficient and time-effective ways (McDonald, Beckham, Morey, \& Calhoun, 2009). Secondly, there is a need to timeously identify (potential) psychological casualties whose fallout may be preventable through proactive and multidimensional health interventions to enhance their overall level of resilience (Castro, Engel, \& Adler, 2004; Jones, Hyams, \& Wessely, 2003). In other words, the future trajectory of military resilience measures is likely to be informed by what the researchers of this study regard as a 'screen-and-stream' (or SAS) approach, which allowsMMHPs:(1) toscreen military personnel comprehensively by means of a timeously administered, scored and analysed resilience measure and (2) to quickly identify and stream those military personnel whose resilience appears to be compromised towards further assessment and targeted intervention by appropriate MMHPs or support providers.

Operational application in the above framework refers to the practical use of a screening tool in a specific context to support positive outcomes, for example using the BSRS in the military context to identify poor resiliency in order to provide further support and targeted interventions.

\section{Aims}

This article aimed to propose and discuss a practical application of resilience scales generally, and the BSRS in particular, supported by underlying psychometric data. It did so in two parts. Firstly, the CAF measure has been developed and validated by using data from the USAF. The current study thus aimed to provide a preliminary validation of a modified version of the measure (BSRS) for use in the South African Navy (SAN). This was done by exploring three aspects of the psychometric properties of the scale in a SAN sample, namely:

- exploring the psychometric structure of the scale by using confirmatory factor analysis (CFA) within structural equation modelling, and internal reliability analysis
- exploring socio-demographic associates, namely the effects of age, gender and experience (operationalised as years of military service, and number of operational deployments)

- exploring scale validity.

Construct validity was examined by correlating the four fitness components, and total fitness, with a resiliency measure (the Military Resiliency Scale [MRS]) to replicate the analysis of Bowen et al. (2016a). Convergent validity was further examined by correlating the four fitness components, and total fitness, with a measure of emotional self-regulation (the Brunel Mood State Scale [BRUMS]), as a proxy for psychological adaptation, in a sample of deployed sailors.

Thereafter, given the criticism of resilience scales regarding the management of individual or group specific findings in practical terms, and based on the demonstrated psychometric data, this article further aimed to propose and discuss an operational application of the BSRS beyond its limited use as a resilience marker in formal research.

\section{Methods}

\section{Participants}

The study was conducted according to the principles set out in the Declaration of Helsinki (World Medical Association, 2013), and had received prior ethical approval from Stellenbosch University. South African Navy sailors on active duty were invited to participate anonymously in the study and were briefed that completion of the measures indicated consent. A total of 1312 SAN sailors (women $=21.4 \%$, men $=$ $78.6 \%)$ returned completed data sets. Table 2 presents the sample composition. A subsample $(N=275)$, drawn from two warships, also completed the BRUMS during operational deployments. They indicated code numbers on the BSRS for later correlation to their BRUMS scores. All data were anonymised prior to analysis.

All participants had a minimum of 12 years of formal education, and all 11 South African official languages were spoken within the sample. The scale was administered in English, as the sample was considered to be proficient in English, which is the official command language of the SAN, and the language in which all training takes place.

\section{Measurements}

Brief Sailor Resiliency Scale: The BSRS is based on the CAF measure of Bowen et al. (2016a, 2016b), and so named to fit

TABLE 2: South African Navy sample composition $(N=1312)$.

\begin{tabular}{llccc}
\hline Variable & Sample & $\boldsymbol{M}$ & SD & Range \\
\hline Age (in years) & Full sample & 31.1 & 7.6 & $20-62$ \\
& Women & 29.2 & 5.6 & $21-58$ \\
& Men & 31.6 & 8.0 & $20-62$ \\
Years of service & Full sample & 10.1 & 7.3 & $1-42$ \\
& Women & 8.3 & 5.6 & $1-38$ \\
& Men & 10.5 & 7.7 & $1-42$ \\
Number of operational deployments & Full sample & 2.3 & 3.5 & $0-30$ \\
& Women & 1.3 & 1.9 & $0-10$ \\
& Men & 2.6 & 3.8 & $0-30$ \\
\hline
\end{tabular}

$M$, mean; SD, standard deviation. 
into the terminology framework employed by the SAN. The BSRS is a 12-item measure of the four fitness components (namely mental, physical, social and spiritual), which can be calculated to obtain a comprehensive fitness score. Each fitness component is measured by means of three indicators. Data from the USAF indicate that the scale consists of four distinct first-order factors with high levels of internal consistency within factors, and that all four factors load onto a second-order factor of comprehensive fitness. Good construct validity has been demonstrated (Bowen et al., 2016a, 2016b). All items were completed using a Likert scale format (anchored at 0 - not at all and 4 - completely). This 5-point Likert scale differed from the original CAF measure, which employed an 11-point scale; the range was chosen to be aligned to other measures used in the local SAN context, which typically uses 5-point scale formats. The 11-point range was further narrowed to accommodate secondlanguage English speakers - who form the majority of this sample and the SAN in general. Previous experience indicated that second-language English speakers found discerning the semantic nuances in an 11-point scale challenging.

Military Resiliency Scale: The MRS is a self-assessed performance-based measure of military resiliency (Bowen et al., 2016a), consisting of three observed variables that tap human performance within military service life (Bowen \& Martin, 2013). Responses are indicated on a 5-point Likert scale; support for validity indicators (Bowen \& Martin, 2013), as well as an alpha coefficient of 0.81 (Bowen et al., 2016a), was reported previously.

Brunel Mood State Scale: The BRUMS is a 24-item selfreport inventory that measures mood states on a 5-point Likert scale (McNair, Heuchert, \& Shilony, 2003; Terry, Lane, \& Fogarty, 2003). Good concurrent and criterion validity, as well as reliability, have been reported both internationally (McNair et al., 2003; Terry et al., 2003) and locally (Terry, Potgieter, \& Fogarty, 2003). Among others, it has been used during military deployments to predict selfreported post-traumatic stress symptoms after maritime interdiction operations (Van Wijk, Martin \& Hans-Arendse, 2013). The BRUMS is sensitive to changes in emotional regulation, and is regularly used in the SAN as an indicator of psychological adaptation during operational deployments in specific ICE contexts (Institute for Maritime Medicine, 2018). In this context, adaptation is a proxy for resiliency (i.e. an outcome of resilience), and BRUMS total scores were used for correlation to BSRS scores to examine convergent validity.

\section{Data analysis}

Descriptive analysis was conducted through score distribution and tests of normality. The psychometric structure of the scale was examined by CFA within structural equation modelling, and internal reliability analysis. Confirmatory factor analysis is a special form of factor analysis, used to test whether data fit a hypothesised measurement model (Marker, 2002). With the original factor structure of the scale established in USAF samples, CFA was employed to verify the relationships between the observed variables and their underlying latent constructs in a local SAN sample. Further information on CFA indices can be found in Appendix 1 - Table 2-A1. Socio-demographic effects were examined by using bivariate correlation coefficients (for age and experience) and independent $t$-tests (for gender). Construct validity was also examined by using bivariate correlation coefficients of BSRS scores and MRS and BRUMS scores. All analyses were conducted by means of Statistical Package for Social Sciences (SPSS version 25) and analysis of moment structures (AMOS).

\section{Ethical consideration}

The study received approval from the Health Research Ethics Committee of Stellenbosch University (protocol number: N16/04/051).

\section{Results Normality distribution}

The total fitness score had a mean of 38.3 and a standard deviation of \pm 6.4. It is graphically represented in Appendix 1, Figure 1-A1. Tests of univariate normality were conducted, and it was found that all skew index values were less than 2 and all kurtosis index values were less than 3 (Appendix 1, Table 1-A1), thus indicating that the distributions of responses were not necessarily problematic (George \& Mallery, 2010).

\section{Confirmatory factor analysis}

The 12-item BSRS was subjected to CFA, and the results associated with the final model are displayed in Figure 1. The model yielded acceptable fit, as indicated by the following model fit indices: $\chi^{2}(48)=159.59, p<0.001$; root mean square error of approximation (RMSEA) $=0.042(95 \%$ confidence interval [CI]: 0.035-0.049); comparative fit index (CFI) = 0.998; goodness-of-fit index (GFI) $=0.998$; and adjusted goodnessof-fit index $(\mathrm{AGFI})=0.995$. Standardised first-order factor loadings ranged from 0.78 to 0.94 , and second-order factor loadings ranged from 0.70 to 0.78 . Expanded goodness-of-fit indices and factor correlations can be found in Appendix 1, Tables 2-A1 and 3-A1.

\section{Reliability}

The 12-item BSRS comprehensive fitness scale produced a Cronbach's alpha $(\alpha)$ of 0.874 . Mental fitness $(\alpha=0.745)$, physical fitness $(\alpha=0.851)$, social fitness $(\alpha=0.873)$ and spiritual fitness, $(\alpha=0.892)$ all produced acceptable alphas. Apart from mental fitness, which differed somewhat from $\alpha=0.90$ reported in the validation studies, the rest were similar to published reports (cf. Bowen et al., 2016a, 2016b).

\section{Socio-demographic associations}

The correlations between BSRS and age, years of military service and number of operational deployments are presented 


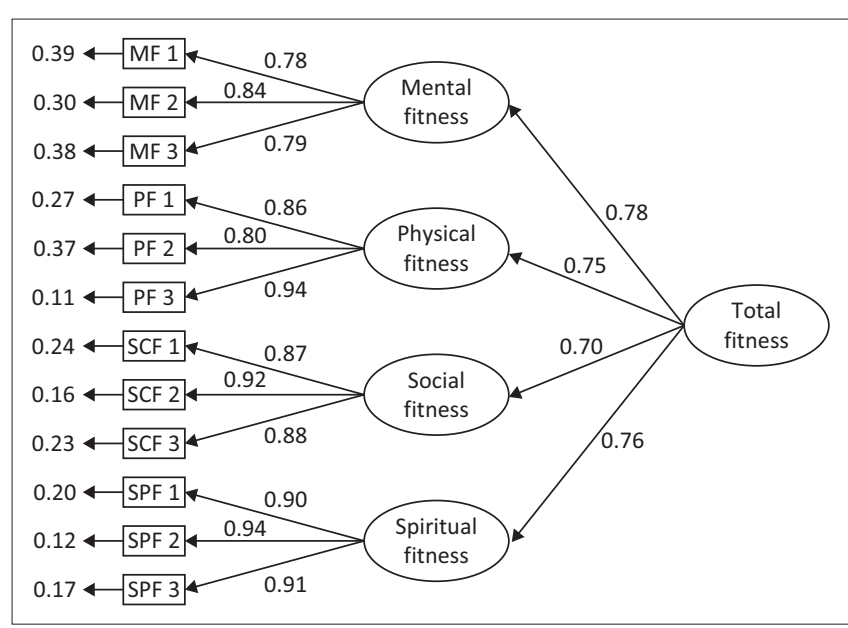

Note: Values in the left column reflect variance; other values reflect item loading. MF, Mental fitness; PF, Physical fitness; SCF, social fitness; SPF, spiritual fitness FIGURE 1: Final model with standardised estimated parameters.

TABLE 3: Correlations between socio-demographic variables and Brief Sailor Resiliency Scale comprehensive fitness scores.

\begin{tabular}{llcc}
\hline Variable & Sample & $\boldsymbol{r}$ & $\boldsymbol{p}$ \\
\hline Age (in years) & Full sample & 0.19 & $<0.001$ \\
& Women & 0.11 & 0.074 \\
& Men & 0.20 & $<0.001$ \\
Years of service & Full sample & 0.22 & $<0.001$ \\
& Women & 0.13 & 0.027 \\
& Men & 0.22 & $<0.001$ \\
Number of operational deployments & Full sample & 0.13 & $<0.001$ \\
& Women & 0.05 & 0.415 \\
& Men & 0.13 & $<0.001$ \\
\hline
\end{tabular}

in Table 3. Men scored higher than women $(t=4.160, p<0.001$, Cohen's $d=0.28$, mean difference $=1.8$ ), although the actual size of the difference was very small.

\section{Scale validity}

The correlations between the BSRS first- and second-order factors and the measure of resiliency are presented in Table 4, as are the correlations with a measure of emotional regulation. Brief Sailor Resiliency Scale's total and component scores all predicted resiliency ( $p<0.001$ for all), as well as emotional regulation (as a proxy for psychological adaptation; $p<0.001$ for all) during an operational deployment.

\section{Discussion}

\section{Preliminary validation of the Brief Sailor Resiliency Scale in the South African Navy context}

The findings provide a preliminary validation of the BSRS for use in the SAN. The analysis confirmed the previously reported factor structure and internal reliability (Bowen et al., 2016a, 2016b). The findings support the model of four distinct fitness domains (mental, physical, social and spiritual) that can be considered to contribute towards a more global measure, namely the second-order factor of comprehensive fitness. It was noteworthy that the variables age, years of military service and number of operational deployments, all displayed similar trajectories, suggesting
TABLE 4: Brief Sailor Resiliency Scale construct validity indicators.

\begin{tabular}{lccccc}
\hline Variable & \multicolumn{2}{c}{$\begin{array}{c}\text { Resiliency } \\
\text { (MRS) }\end{array}$} & & \multicolumn{2}{c}{$\begin{array}{c}\text { Emotional regulation } \\
\text { (BRUMS) }\end{array}$} \\
\cline { 2 - 3 } \cline { 6 - 7 } & $\boldsymbol{r}$ & $\boldsymbol{p}$ & & $\boldsymbol{r}$ & $\boldsymbol{p}$ \\
\hline Comprehensive fitness & 0.52 & $<0.001$ & & -0.48 & $<0.001$ \\
Mental fitness & 0.44 & $<0.001$ & & -0.52 & $<0.001$ \\
Physical fitness & 0.34 & $<0.001$ & & -0.47 & $<0.001$ \\
Social fitness & 0.40 & $<0.001$ & & -0.26 & $<0.001$ \\
Spiritual fitness & 0.39 & $<0.001$ & & -0.26 & $<0.001$ \\
\hline
\end{tabular}

MRS, Military Resiliency Scale; BRUMS, Brunel Mood State Scale.

that all three may be tapping into the same construct, perhaps in this case 'life experience', which is generally operationalised as age. Although small variations across gender and age were observed, this could be because of the distribution of age and discrepant gender subgroups, and would likely not have practical significance in the application of the BSRS. Furthermore, the findings replicated support for the construct validity of the scale (Bowen et al., 2016a), and further extended support for its validity, in that BSRS score outcomes appeared to predict actual psychological adaptation in ICE contexts. In practice, this may mean that some indicators of problematic adaptation during ICE missions could possibly be predicted in advance with the BSRS, leading the way towards considering timely intervention.

\section{Operational application: Towards a screen-and-stream approach}

The establishment of preliminary psychometric properties sets the scene for considering the operational application of resilience scales, referring to its use in specific contexts. In this regard, the findings of this study appear to support the contention that comprehensive resilience screening measures, while brief and time-effective, such as the BSRS, hold both occupational and operational health benefits for military personnel, broadly, and naval personnel, in particular. While the BSRS appears psychometrically valid in providing an overall measure of comprehensive fitness, it demonstrates its operational application through the psychometrically sound and nuanced rendering of resiliency through subscales of mental, physical, social and spiritual fitness. The use of the BSRS therefore provides a screening measure of specific core dimensions, which underwrite the overall resilience of military personnel, and in effect aid in assessing the resilience dimension of a particular sailor's combat and operational readiness. In doing so, MMHPs who use the BSRS are provided with clear psychometric indicators concerning those sailors - be they individuals or teams - who may require further assessment and perhaps benefit from targeted resilience-enhancing interventions.

In the South African National Defence Force, much like many other militaries around the world (Firth \& Smith, 2010), the occupational health and welfare of military service personnel is regarded as multifaceted and informed by physiological (e.g. biological), psychological (e.g. emotional), social (e.g. familial) and spiritual (e.g. religio-cultural belief system) determinants (South African Military Health Service, 2008). To this effect, the practice of military health support and 
service provision is often circumscribed by the involvement of multi-professional teams which involve the coparticipation of various health and support professionals, such as physicians, psychologists, social workers and chaplains, who work together to collectively manage, treat and proactively enhance the occupational well-being and, by extension, operational health and utility of military personnel.

While comprehensive military health support systems are necessary for sustaining the health of operationally active military personnel, such systems are also prone to laborious, time-intensive and often over-burdened and under-staffed referral channels. As a consequence, operationally at-risk individuals may 'get lost in the system' or 'fall through the cracks' because of poorly articulated or inefficient referrals for further assessment and intervention. However, the BSRS provides a concise multidimensional screening of resilience, through which specific dimensions of potentially compromised resilience can be identified and 'streamed' to the most appropriate MMHP or support professional for further assessment and intervention. In this regard, the BSRS becomes especially valuable for the MMHPs who work with the operationally active sailors of the SAN, whose military work and life is increasingly characterised by regular deployments and a high operational tempo by virtue of the leading role that the SAN plays in maritime border patrol (defenceWeb, 2019) and multinational anti-piracy operations along the southern coasts of Africa (defenceWeb, 2018).

Importantly, the SAS approach is by no means limited to naval or general military contexts, and could also be considered for translation and application in other occupational environments with exposure to challenging conditions, and which require ongoing and meaningful modes of adaptation to the operational demands placed on those personnel. Such occupational contexts may range from the South African Police Service or Emergency Medical or Rescue Services to the offshore industry that typically lives and works in ICE conditions.

\section{Limitations and future directions}

The briefness of the subscales, and the very high values of the model fit indices, may suggest some over-fitting or saturation of the BSRS model (Marker, 2002), and caution is advised when interpreting these results. Further research using different data sets may assist to resolve this concern.

The study used a limited array of markers to represent the outcome of resilience, and future studies may need to extend the measuring of psychological adaptation and mental health, as well as the measuring of actual work performance to enhance understanding of the relationship between comprehensive sailor fitness and well-being in the naval context. Further research is also required to establish the extent to which this model can be transferred to other related occupational contexts.

Another issue worth noting is the conceptualisation of spiritual fitness within the BSRS. Although the measure of spiritual fitness in this research was found to be both valid and reliable, the operationalisation of the spiritual fitness subscale and items adhered quite closely to the original CAFbased articulation of spiritual fitness in the USAF environment. To this effect, it may still be necessary to broaden the conceptualisation of spiritual fitness for SAN sailors who draw from diverse, intersecting and often competing religio-cultural, indigenous and cosmological systems which inform how they understand and sustain spiritual fitness as a facet of personal resilience within the military environment.

\section{Conclusion}

This study established the potential of the BSRS to assess for resilience outcomes among SAN sailors. It further proposes an operational application, namely a 'screen-and-stream' model, as a valid and cost-effective way to provide appropriate support to individuals and groups with potentially compromised aspects of resilience.

\section{Acknowledgements}

The authors wish to thank Prof. M. Kidd for support with the structural equation modelling.

\section{Competing interests}

The authors declare that they have no financial or personal relationships that may have inappropriately influenced them in writing this article.

\section{Authors' contributions}

All authors contributed equally to this work by collecting the data, analysing the results and writing the manuscript.

\section{Funding}

No funding was received for this study.

\section{Data availability statement}

The data is from a military sample, and thus not available for sharing.

\section{Disclaimer}

The views expressed in this article are the authors' own and not an official position of the institutions or funders.

\section{References}

Adler, A.B., \& Sowden, W.J. (2018). Resilience in the military: The double-edged sword of military culture. In L.W. Roberts (Ed.), Military and veteran mental health: A comprehensive guide (pp. 43-54). New York: Springer.

Air Force Instruction 90-506. (2014 April 02). Comprehensive airman fitness (CAF). Washington, DC: Department of the Air Force.

American Psychological Association (2019). The road to resilience. Retrieved from https://www.apa.org/helpcenter/road-resilience.aspx.

Bartone, P.T. (1989). Predictors of stress-related illness in city bus drivers. Journal of Occupational Medicine, 31(8), 657-663. https://doi.org/10.1097/00043764198908000-00008

Bartone, P.T. (1996, August). Stress and hardiness in U.S. peacekeeping soldiers. Paper presented at the 104th American Psychological Association meeting, Toronto, Canada. 
Bartone, P.T. (1999). Hardiness protects against war-related stress in army reserve forces. Consulting Psychology Journal, 51(2), 72-82. https://doi.org/10.1037/ forces. Consulting

Bartone, P.T. (2000). Hardiness as a resiliency factor for United States forces in the Gulf War. In J.M. Violanti, D. Paton \& C. Dunning (Eds.), Posttraumatic stress intervention: Challenges, issues, and perspectives (pp. 115-133). Springfield, IL: C.Thomas.

Bartone, P.T., Hystad, S.W., Eid, J., \& Brevik, J.I. (2012). Psychological hardiness and coping style as risk/resilience factors for alcohol abuse. Military Medicine, 177(5), 517-524. https://doi.org/10.7205/MILMED-D-11-00200

Bartone, P.T., Johnsen, B.H., Eid, J., Laberg, L.C., \& Brun, W. (2002). Factors influencing small unit cohesion in Norwegian navy officer cadets. Military Psychology, 14(1) 1-22. https://doi.org/10.1207/S15327876MP1401_01

Bartone, P.T., Roland, R.R., Picano, J.J., \& Williams, T.J. (2008). Psychological hardiness predicts success in US Army Special Forces candidates. International Journal of Selection and Assessment, 16(1), 78-81. https://doi.org/10.1111/j.1468 2389.2008.00412.x

Bartone, P.T., Ursano, R.J., Wright, K.M., \& Ingraham, L.H. (1989). The impact of a military air disaster on the health of assistance workers: A prospective study. Journal of Nervous and Mental Disease, 177(6), 317-328. https://doi. org/10.1097/00005053-198906000-00001

Bowen, G.L., Jensen, T.M., \& Martin, J.A. (2016a). A measure of comprehensive airman fitness: Construct validation and invariance across air force service components. Military Behavioral Health, 4(2), 149-158. https://doi.org/10.1080/ 21635781.2015.1133345

Bowen, G.L., Jensen, T.M., \& Martin, J.A. (2016b). Confirmatory factor analysis of a measure of comprehensive airman fitness. Military Behavioral Health, 4(4), 409419. https://doi.org/10.1080/21635781.2016.1199984

Bowen, G.L., \& Martin, J.A. (2011). The resiliency model of role performance of service members, veterans, and their families. Journal of Human Behavior in the Social Environment, 21(2), 162-178. https://doi.org/10.1080/10911359.2011.54 6198

Bowen, G.L., \& Martin, J.A. (2013). Support and resiliency inventory (SRI-M): Sixmonth utilization report (January-June 2013). Charlotte, NC: Flying Bridge Technologies. Retrieved from https://doi.org/10.13140/2.1.1536.0327

Britt, T.W., Adler, A.B., \& Bartone, P.T. (2001). Deriving benefits from stressful events: The role of engagement in meaningful work and hardiness. Journal of Occupational Health Psychology, 6(1), 53-63. https://doi.org/10.1037/1076-8998.6.1.53

Castro, C.A., Engel, C.C., \& Adler, A.B. (2004). The challenge of providing mental health prevention and early intervention in the US military. In B.T. Litz (Ed.), Early intervention for trauma and traumatic loss (pp. 301-318). New York: Guilford Press.

Clough, P., Earle, K., \& Sewell, D. (2002). Mental toughness: The concept and its measurement. In I. Cockerill (Ed.), Solutions in sport psychology (pp. 32-46). London: Thomson Learning.

defenceWeb. (2018). SA navy two platform deployment returns from Op Copper duty. Retrieved from https://www.defenceweb.co.za/security/maritime-security/sanavy-two-platform-deployment-returns-from-op-copper-duty/.

defenceWeb. (2019). Makhanda on maritime resource protection tasking. Retrieved from https://www.defenceweb.co.za/featured/makhanda-on-maritimeresource-protection-tasking/.

Escolas, S.M., Pitts, B.L., Safer, M.A., \& Bartone, P.T. (2013). The protective value of hardiness on military posttraumatic stress symptoms. Military Psychology, 25(2), hardiness on military posttraumatic stress sympt

Firth, K.M., \& Smith, K. (2010). A survey of multidimensional health and fitness indexes. Military Medicine, 175(suppl 8), 110-117. https://doi.org/10.7205/ MILMED-D-10-00257

George, D., \& Mallery, M. (2010). SPSS for Windows step by step: A simple guide and reference (17.0 update, 10a edn.). Boston, MA: Pearson.

Gerber, M., Feldmeth, A.K., Lang, C., Brand, S., Elliott, C., Holsboer-Trachsler, E., \& Pühse, U. (2015). The relationship between mental toughness, stress and burnout among adolescents: A longitudinal study with Swiss vocational students. Psychological Reports: Employment Psychology \& Marketing, 117(3), 703-723. https://doi.org/10.2466/14.02.PRO.117c29z6

Giles, B., Goods, P.S.R., Warner, D.R., Quain, D., Peeling, P., Ducker, K.J., ... Gucciardi, D.F. (2018). Mental toughness and behavioural perseverance: A conceptual replication and extension. Journal of Science and Medicine in Sport, 21(6), 640-645. https://doi.org/10.1016/j.jsams.2017.10.036
Greene, C.H., \& Staal, M.A. (2017). Resilience in US special operations forces. In S.V. Bowles \& P.T. Bartone (Eds.), Handbook of military psychology: Clinical and organizational practice (pp. 177-192). Champaign, IL: Springer.

Institute for Maritime Medicine (2018). Usefulness of the BRUMS for mobilisation/ demobilisation of ship-based maritime operations. Technical Report 14 December 2018. Simon's Town: Institute for Maritime Medicine.

Jones, E., Hyams, K.C., \& Wessely, S. (2003). Screening for vulnerability to psychological disorders in the military: An historical survey. Journal of Medical Screening, 10(1) 40-46. https://doi.org/10.1258/096914103321610798

Kobasa, S.C. (1979). Stressful life events, personality and health: An inquiry into hardiness. Journal of Personality and Social Psychology, 37(1), 1-11. https://doi. org/10.1037/0022-3514.37.1.1

Kobasa, S.C, Maddi, S.R., \& Kahn, S. (1982). Hardiness and health: A prospective study. Journal of Personality and Social Psychology, 42(1), 168-177. https://doi. org/10.1037/0022-3514.42.1.168

Lee, J.E., Sudom, K.A., \& Zamorski, M.A. (2013). Longitudinal analysis of psychological resilience and mental health in Canadian military personnel returning from overseas deployment. Journal of Occupational Health Psychology, 18(3), 327-337. https://doi.org/10.1037/a0033059

Maddi, S.R., \& Hess, M. (1992). Hardiness and success in basketball. Internationa Journal of Sports Psychology, 23(4), 360-368.

Maddi, S.R., \& Kobasa, S.C. (1984). The hardy executive: Health under stress. Homewood, IL: Dow Jones Irwin.

Marker, D. (2002). Model theory: An introduction. New York: Springer-Verlag.

Martin, J., Van Wijk, C., Hans-Arendse, C., \& Makhaba, L. (2013). 'Missing in action': The significance of bodies in African bereavement rituals. Psychology in Society, 44, 42-63.

McDonald, S.D., Beckham, J.C., Morey, R.A., \& Calhoun, P.S. (2009). The validity and diagnostic efficiency of the Davidson Trauma Scale in military veterans who have served since September 11th, 2001. Journal of Anxiety Disorders, 23(2), 247-255. https://doi.org/10.1016/j.janxdis.2008.07.007

McNair, D.M., Heuchert, J.W.P., \& Shilony, E. (2003). Profile of mood states manual: Bibliography 1964-2002. New York: Multi- Health Systems Inc.

Morgan, B.J., \& Bibb, S.C.G. (2011). Assessment of military population-based psychological resilience programs. Military Medicine, 176(9), 976-985. https:// doi.org/10.7205/MILMED-D-10-00433

Pietrzak, R.H., Johnson, D.C., Goldstein, M.B., Malley, J.C., \& Southwick, S.M. (2009) Psychological resilience and post-deployment social support protect against traumatic stress and depressive symptoms in soldiers returning from operations Enduring Freedom and Iraqi Freedom. Depression and Anxiety, 26, 745-751. https://doi.org/10.1002/da.20558

Simmons, A., \& Yoder, L. (2013). Military resilience: A concept analysis. Nursing Forum, 48(1), 17-25. https://doi.org/10.1111/nuf.12007

Smallidge, T., Jones, E., Lamb, J., Feyre, R., Steed, R., \& Caras, A. (2013). Modelling complex tactical team dynamics in observed submarine operations. In D.D. Schmorrow \& C.M. Fidopiastis (Eds.), Foundations of augmented cognition (pp. 189-198). Berlin: Springer.

South African Military Health Service (2008). South African military health service: Conventional doctrine. Pretoria: South African Military Health Service.

Terry, P.C., Lane, A.M., \& Fogarty, G.J. (2003). Construct validity of the POMS-A for use with adults. Psychology of Sport and Exercise, 4(2), 125-139. https://doi. org/10.1016/S1469-0292(01)00035-8

Terry, P.C., Potgieter, J.R., \& Fogarty, G.J. (2003). The Stellenbosch mood scale: A duallanguage measure of mood. International Journal of Sport and Exercise Psychology, 1(3), 231-245. https://doi.org/10.1080/1612197X.2003.9671716

Van Wijk, C.H., Martin, J.H., \& Hans-Arendse, C. (2013). Clinical utility of the BRUMS in screening for post-traumatic stress risk in a military population. Military Medicine, 178(4), 372-376. https://doi.org/10.7205/MILMED-D-12-00422

World Medical Association. (2013). Declaration of Helsinki. Journal of the American Medical Association, 310(20), 2191-2194. https://doi.org/10.1001/jama.2013. 281053

Wright, K.M., Riviere, L.A., Merrill, J.C., \& Cabrera, O.A. (2013). Resilience in military families: A review of programs and empirical evidence. In R.R. Sinclair \& T.W. Britt (Eds.), Building psychological resilience in military personnel: Theory and practice (pp. 167-191). Washington, DC: American Psychological Association.

Xie, Y., Peng, L., Zuo, X., \& Li, M. (2016). The psychometric evaluation of the ConnorDavidson resilience scale using a Chinese military sample. PLoS One, 11(2), e0148843. https://doi.org/10.1371/journal.pone.0148843 


\section{Appendix 1}

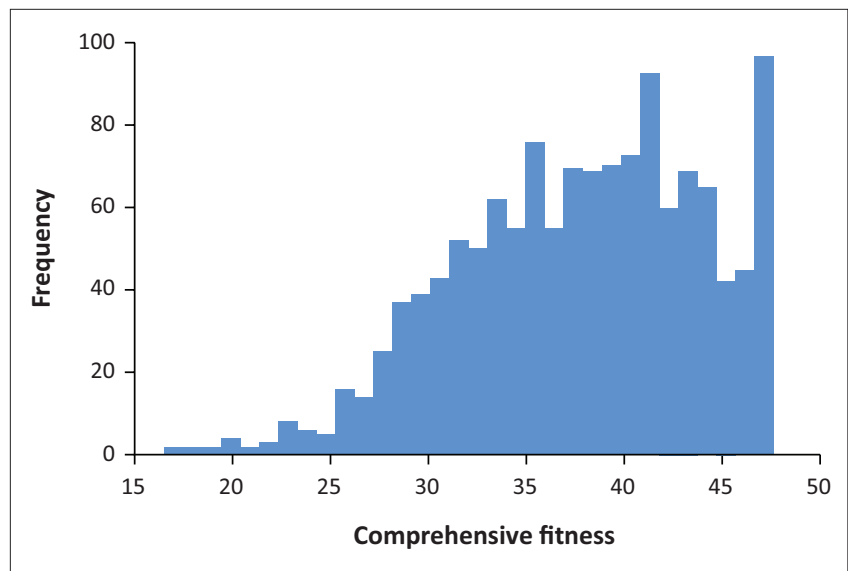

FIGURE 1-A1: Distribution of the comprehensive fitness score.

TABLE 1-A1: Normality metrics for the Brief Sailor Resiliency Scale $(N=1312)$.

\begin{tabular}{lcccc}
\hline & $\boldsymbol{M}$ & SD & Skewness & Kurtosis \\
\hline Comprehensive fitness & 38.30 & 6.4 & -0.467 & -0.220 \\
Mental fitness & 10.39 & 1.6 & -0.998 & 1.050 \\
MF 1 & 3.38 & 0.7 & -1.036 & 0.768 \\
MF 2 & 3.63 & 0.6 & -1.267 & 1.059 \\
MF 3 & 3.39 & 0.7 & -0.793 & 0.478 \\
Physical fitness & 8.79 & 2.2 & -0.354 & -0.331 \\
PF 1 & 2.97 & 0.8 & -0.468 & -0.127 \\
PF 2 & 2.78 & 0.9 & -0.284 & -0.528 \\
PF 3 & 3.04 & 0.8 & -0.423 & -0.384 \\
Social fitness & 8.99 & 2.7 & -0.691 & -0.143 \\
SCF 1 & 3.18 & 1.0 & -1.019 & 0.322 \\
SCF 2 & 3.00 & 1.0 & -0.727 & -0.142 \\
SCF 3 & 2.81 & 1.0 & -0.518 & -0.456 \\
Spiritual fitness & 10.13 & 2.1 & -1.348 & 2.378 \\
SPF 1 & 3.46 & 0.8 & -1.567 & 2.895 \\
SPF 2 & 3.35 & 0.8 & -1.244 & 2.062 \\
SPF 3 & 3.31 & 0.8 & -1.282 & 2.122 \\
\hline
\end{tabular}

$M$, mean; SD, standard deviation; MF, Mental fitness; PF, Physical fitness; SCF, social fitness; SPF, spiritual fitness.
TABLE 2-A1: Goodness-of-fit indices for the Brief Sailor Resiliency Scale.

\begin{tabular}{llcl}
\hline Indices & Result & Requirement & Outcome \\
\hline RMSEA & 0.042 & $<0.06$ & Acceptable fit \\
$p$-value & 0.962 & - & - \\
$95 \% \mathrm{Cl}$ & $0.035-0.049$ & - & - \\
$\chi^{2}$ & 159.59 & - & Questionable fit \\
$p$-value & $<0.001$ & $>0.05$ & - \\
$d f$ & 48 & ratio $\chi^{2}$ to $d f \leq 3$ & - \\
CFI & 0.998 & $>.95$ & Acceptable fit \\
GFI & 0.998 & $>.95$ & Acceptable fit \\
AGFI & 0.995 & $>.95$ & Acceptable fit \\
AVE & & & \\
Mental fitness & 0.64 & $>0.50$ & Acceptable \\
Physical fitness & 0.75 & - & Acceptable \\
Social fitness & 0.74 & - & Acceptable \\
Spiritual fitness & 0.74 & - & Acceptable \\
CR & & $>0.70$ & Acceptable \\
Mental fitness & 0.84 & - & Acceptable \\
Physical fitness & 0.90 & - & Acceptable \\
Social fitness & 0.92 & - & Acceptable \\
Spiritual fitness & 0.94 & &
\end{tabular}

RMSEA, root mean square error of approximation; $\mathrm{CFI}$, comparative fit index; $\mathrm{GFI}$, goodnessof-fit index; AGFI, adjusted goodness-of-fit index; AVE, average value explained; CR, critical ratio; $\mathrm{Cl}$, confidence interval.

TABLE 3-A1: Brief Sailor Resiliency Scale factor correlations

Domains Mental fitness Physical fitness Social fitness Spiritual fitness

Mental fitness

Physical fitness $\quad 0.69$

Social fitness $\quad 0.51$

Spiritual fitness $\quad 0.58$ 